\title{
IAMJ
}

INTERNATIONAL

AYURVEDIC

MEDICAL JOURNAL

\section{A COMPARATIVE CLINICAL STUDY OF A HERBO-MINERAL COMPOUND DHATRI LAUHA WITH A CONTROL KNOWN DRUG IN THE MANAGEMENT OF PANDU ROGA W.S.R. TO IRON DEFICIENCY ANEMIA}

\author{
$\underline{\text { Roshi Mahajan }}^{1}, \underline{\text { Ankita }}^{2}$ \\ ${ }^{1}$ Assistant Professor, Department of Roga Nidana, Govt. Ayurvedic Medical College, Jammu, India \\ ${ }^{2}$ Assistant Professor, Department of Samhita \& Siddhanta, Govt. Ayurvedic Medical College, Jammu, India
}

Corresponding Author: ullas.ankita@gmail.com

https://doi.org/10.46607/iamj0609042021

(Published Online: April 2021)

Open Access

(C) International Ayurvedic Medical Journal, India 2021

Article Received:05/04/2021 - Peer Reviewed:13/04/2021 - Accepted for Publication:14/04/2021

Check for updates

\section{ABSTRACT}

Humans are progressively achieving new heights in the development of science and technology but at the same time it is difficult to follow the ways of healthy living as a consequence of which people are getting prone to many diseases. Among them "Anemia" is a very common disease, seen especially in developing countries like India. It reduces the work capacity of individuals and brings serious economic consequences and obstacles to the National Development. In this study, an effort has been put upon to explore the hidden potential laid in Ayurveda. So, in this research work, a comparative study was conducted between a herbo-mineral compound - Dhatri Lauha with a controlled group known drug. In the present study, total 30 patients were registered and randomly divided into two groups. Group A: 15 patients were included in this group and were given Dhatri Lauha 500mg BD orally. Group B: 15 patients were included in this group and were given dried Ferrous Sulphate 150mg OD orally. The patients were assessed on subjective and hematological parameters for obtaining the effect of the drugs. Both the groups yielded highly significant results in subjective parameters. Again, highly significant and significant relief was seen in Nausea and constipation respectively in Group A whereas Group B showed insignificant results regarding nausea and constipation. The study Overall comparison of the therapy showed that the results were found better with high percentage relief in the patients under Trial Group i.e. Dhatri Lauha in comparison to the 
Control Group. The study concluded that the selected management has potential effect on Pandu Roga with the added advantage of being free from side effects.

Keywords: Herbo-mineral, DhatriLauha, hematological, Pandu roga.

\section{INTRODUCTION}

It is a great irony "While the poor are not able to afford a good diet, and the rich due to their fondness for junk food, do not eat a balanced diet." Thus, malnutrition either due to inadequate dietary intake or lack of balanced diet and population explosion has led to the development of various diseases and Anemia is one such disease. Globally $30 \%$ of the total population is Anemic and half of these suffer from Iron deficiency Anemia (IDA). According to WHO, 50\% of children and women and $25 \%$ of men in developing countries like India are suffering from Iron Deficiency Anemia ${ }^{1}$. 9 out of 10 people living in developing countries are the sufferers of Iron Deficiency Anaemia ${ }^{2}$. IDA is associated with cognitive impairment, reduced work output, and is an important contributor to maternal and peri-natal mortality. This compelled W.H.O. to declare it as a world health problem. IDA is the most common type of Anemia met in clinical practice and the most prevalent nutritional deficiency in the world. The word Anemia is derived from Greek language which means "Lack of blood" 3 . The disease is characterized by reduction in the $\mathrm{Hb} \mathrm{g} \%$ and No. of RBC's /cu mm of blood there by reducing the oxygen carrying capacity of blood resulting in pallor like other symptoms.

Pandu Roga is a disease characterized by pallor of body which strikingly resembles with 'Anaemia' of Modern science. In all the Ayurvedic texts, the word Pandu may find its description as a disease, as a sign or symptom or as a complication. In Charaka Samhita, Pandu Roga has been described in Sutra - Sthana in the Chapter "Ashtodariya Adhyaya". Pandu Roga is a Pitta Pradhana Vyadhi and since Pitta Dosha is responsible for normal colour of the body, so, if it gets vitiated, impairment of colour and complexion (Panduta) occurs. Thus, disease characterized by Pandu Varna due to significant deficiency of Rakta Dhatu is known as Pandu Roga. Pandu Varna is a mixture of
Shweta \& Peeta Varnas which resembles the colour of pollen grains of Ketaki flower ${ }^{5}$. Moreover, this vitiated Pitta Dosha leads to Dhatu-shaithilya (loosening of Dhatus), Dhatu-gaurava (heaviness in Dhatus), as a result of Balakshaya (loss of physical strength), Ojokshaya (loss of immunity) and Varnanasha (loss of complexion) occur ${ }^{6}$.The person with this disease suffers from decreased blood amount, strength and complexion, becomes insipid i.e. Nisara (loss of natural integrity, tone and strength of Dhatus).Thus, the Pandu Rogi is stated to be affected with Raktalpta (decreased Rakta), Medalpata (decreased Meda dhatu), Nisarata (reduced valour), Vaivarnata (discoloration) and Shithilaindriya (slow sensory perception) ${ }^{7}$.Our great Acharyas have mentioned the use of Lauha dhatu in the treatment of Pandu at many places. An attempt is made to explore the vast Ayurvedic heritage from herbo-mineral drugs to find out a satisfactory treatment of Pandu Roga. Thus, keeping in view, a comparative study of Dhatri lauha ${ }^{8}$ with controlled known drug in the management of Pandu Roga w.s.r. to Iron Deficiency Anemia" was designed and conducted to evaluate the efficacy of our trial drug in the management of anemia.

\section{Aim and Objectives}

1. Conceptual study of Pandu roga vis-à-vis Iron Deficiency Anemia.

2. To evaluate the effect of an Ayurvedic formulation i.e. Dhatri Lauha in the management of Pandu roga on clinical parameters.

3. To compare the therapeutic effects of Dhatri Lau$h a$ with the known standard compound trusted from years i.e. Ferrous Sulphate.

\section{Material and Method}

All the 30 patients of Pandu Roga registered for the present trial were assessed for subjective, clinical and hematological improvement before and after the treatment as per International conference of Harmoni- 
zation-Good Clinical Practices Guidelines (ICHGCP). Clinical features were assessed once every month for 2 months and hematological parameters like $\mathrm{Hb}$ g\%, Reticulocyte count, PCV, MCV, MCHC, and P.B.F. were noted before and after the treatment.

\section{Selection of Patients:}

Patients were selected from OPD and IPD of Jammu Institute of Ayurveda And Research Hospital, Jammu. All the patients were clinically diagnosed and registered after taking consent. Details of examinations and investigations were recorded in the Performa.

\section{Inclusion criteria:}

- Patients of either sex between the age group of 18-70 years.

- Patients having hemoglobin concentration:10 - 6 $\mathrm{gm} \%$ in females \&11 - $6 \mathrm{gm} \%$ in males

\section{Exclusion criteria:}

- Age below 18 and above 70 years.

- Patients having hemoglobin less than $6 \mathrm{gm} \%$

- Anemia during pregnancy and lactation.

- Anemia due to other causes i.e. other than Iron Deficiency Anemia.

- Long term infectious systemic disease i.e. - T.B, R.A, AIDS, Leprosy, Malaria, Gout, Malignancies and other systemic diseases like VHD etc.

- Patients who had Gastrectomy, Sprue or severe other gastrointestinal diseases.

\section{Criteria of Assessment:}

Subjective Parameters: Parameters to be assessed before and after the completion of clinical trial on the basis of:

- Pallor
- Fatigue

- Appetite

Objective Parameters:

- $\mathrm{Hb} \mathrm{g} \%$

- Reticulocyte Count

- ESR

- $\mathrm{PCV}$

- $\mathrm{MCV}, \mathrm{MCH}, \mathrm{MCHC}$

- P.B.F

Undue Effects:

- Nausea

- Constipation

\section{Clinical Study}

The registered patients for the clinical trial were randomly divided into two groups:

Group A: 15 patients were included in this group and were given Dhatri Lauha $250 \mathrm{mg}$ BD orally.

Group B: 15 patients were included in this group and were given Ferrous Sulphate $150 \mathrm{mg}$ OD orally.

Duration of Study:

Clinical trial was conducted for the duration of 60 days with the follow up after every 2 weeks to evaluate the therapeutic effect of the drugs. Observations made and results so obtained were computed statistically for appropriate conclusions.

\section{Criteria for assessment of the total effect of thera-} py

Considering the overall improvement shown by the patient in sign \& symptoms, the total effect of the therapy has been assessed as shown in Table 1on the basis of percentage of relief obtained:

Table 1

\begin{tabular}{|l|l|l|}
\hline Cured & $76 \%$ to $100 \%$ & Relief in subjective signs \& symptoms. \\
\hline Markedly improved & $51 \%$ to $75 \%$ & Relief in subjective signs \& symptoms \\
\hline Improved & $26 \%$ to $50 \%$ & Relief in subjective signs \&symptoms. \\
\hline Unchanged & up to $25 \%$ & Relief in some subjective sign \& symptoms \\
\hline
\end{tabular}

Level of Significance

$\mathrm{p}<0.001$ is statistically highly significant

$\mathrm{p}<0.05$ is statistically significant

$p>0.05$ is statistically insignificant 


\section{Results}

Table 2: Comparative analysis between two groups on pallor

\begin{tabular}{|l|l|l|l|l|}
\hline Group & Mean & Mean Diff. & Mean \% \\
\hline B.T. & A.T. & & 56.67 \\
\hline B & 2.47 & 1.07 & 1.4 & 70 \\
\hline
\end{tabular}

Statistical analysis indicates highly significant results of improvement is seen in Group B (70\%) i.e. group B in groups A and group B. But the highest percentage has shown highest improvement in Pallor statistically.

Table 3: Comparative analysis between two groups on fatigue

\begin{tabular}{|l|l|l|l|l|}
\hline Group & Mean & Mean Diff. & Mean \% \\
\hline B.T. & 2.87 & A.T. & 1.54 & 53.65 \\
\hline B & 2.53 & 1.33 & 1.80 & 71 \\
\hline
\end{tabular}

Statistical analysis indicates highly significant results in group A and group B. But the highest percentage of improvement is seen in Group B (71\%) i.e. group B has shown highest improvement in Fatigue statistically.

Table 4: Comparative analysis between two groups on appetite

\begin{tabular}{|l|l|l|l|l|}
\hline Group & Mean & Mean Diff. & Mean \% \\
\hline A.T. & 2 & A.T. & & \\
\hline B & 1.07 & 0.93 & 1.07 & 53.50 \\
\hline Statistican & 0.93 & 0.14 & 13.08 \\
\hline
\end{tabular}

Statistical analysis indicates highly significant results in group A with 53.50\% whereas Group B shows insignificant result (13.08\%). The highest percentage of improvement is seen in Group A i.e. group A has shown highest improvement in Appetite.

Table 5: Comparative analysis between two groups on hemoglobin concentration

\begin{tabular}{|l|l|l|l|l|}
\hline Group & Mean & Mean Diff. & Mean \% \\
\hline B.T. & 8.71 & A.T. & & \\
\hline B & 8.35 & 10.13 & -1.42 & 16.30 \\
\hline
\end{tabular}

Statistical analysis indicates highly significant results in groups A and group B. But the highest percentage of improvement is seen in Group B (18.92\%) i.e. group B has shown highest improvement in Hemoglobin Concentration statistically.

Table 6: Comparative analysis between two groups on Nausea

\begin{tabular}{|l|l|l|l|l|}
\hline Group & Mean & Mean Diff. & Mean \% \\
\hline A.T. & 0.73 & A.T. & & \\
\hline B & 0.53 & 0.2 & 0.53 & 72.60 \\
\hline
\end{tabular}

Statistical analysis indicates highly significant results in group A and Insignificant results in group B and the highest percentage of improvement is seen in Group B (72.60\%) i.e. group B has shown highest improvement in nausea. 
Table 7: Comparative analysis between two groups on constipation

\begin{tabular}{|l|l|l|l|l|}
\hline Group & Mean & Mean Diff. & Mean \% \\
\hline B.T. & 0.8 & A.T. & & \\
\hline A & 0.53 & 0.27 & 0.53 & 66.25 \\
\hline B & 0.73 & -0.2 & 37.73 \\
\hline
\end{tabular}

Statistical analysis indicates significant results in group A and insignificant results in group B and the highest percentage of improvement is seen in Group A (66.25\%) i.e. group A has shown highest improvement in constipation.

Table 8: Similarities between Iron deficiency Anemia and Vataja Pandu Lakshana

\begin{tabular}{|l|l|l|}
\hline S.No. & Iron Deficiency Anaemia & Vataja Pandu Lakshana $^{\mathbf{9}}$ \\
\hline 1. & Pallor of skin mucous membrane, conjunctiva, nails. & Krishna Panduta of Netra, Nakha, Anana, Twaka. \\
\hline 2. & Exertional dyspnoea & Shrama \\
\hline 3. & Lassitude, Fatigue & Angamarda \\
\hline 4. & Weakness & Balakshaya \\
\hline 5. & Anorexia, Indigestion & AsyaVairasya \\
\hline 6. & Brittle nails, Koilonychia & NakhaRukshata \\
\hline 7. & Headache & Shiroshula \\
\hline 8. & Bowel irregularity & Varchashosha, Anaha \\
\hline 9. & Bodyache & Angamarda, Toda Parshashula \\
\hline 10. & Vertigo & Bhrama \\
\hline
\end{tabular}

\section{DISCUSSION}

Anemia is a very common nutritional deficiency prevalent in developing countries. The conceptual study revealed that Pandu roga as a whole cannot be equated with Iron Deficiency Anemia in particular and clinical study showed that Iron deficiency Anemia mainly presented as Vataja Pandu.

The present study has been carried out to analyze the cure rates and compare the effects of Dhatri Lauhawith the known standard compound i.e. Ferrous Sulphate. The whole study was performed in two groups:

\section{Group A - Dhatri Lauha}

2. Group B - Ferrous Sulphate (Control group)

The patients were assessed on different parameters for obtaining the effect of therapies. All clinical signs and symptoms were assessed on the basis of scoring given to them. The general observations revealed that maximum number of patients i.e. $40 \%$ were between the age group of $18-30$ years and $80 \%$ of the cases belonged to females of which $43.33 \%$ patients were housewives. The observations also revealed that $50 \%$ patients were from lower income class.

Incidence of Panduta was found in $100 \%$ of the cases, Aruchi in $93.33 \%$, Daurbalya in $90 \%$. Thus, it was noted that Panduta, Aruchi and Daurbalya were the main presenting symptoms in the patients of Pandu Roga.

While assessing the overall percentage of improvement in both the groups on different clinical parameters, it was noticed that there was $53.15 \%$ improvement in Group A, 39.52\% improvement in Group B.

\section{Mode of Action of Drug}

Table 9: Ingredients of Dhatri Lauha

\begin{tabular}{|l|l|l|}
\hline S.No. & Herb and part used & Quantity \\
\hline 1. & Amalaki (Emblica officinalis L.) Pericarp & 4 parts \\
\hline 2. & LauhaBhasma & 2 parts \\
\hline 3. & Yashtimadhu $($ Glycyrrhiza glabra L.)Root & 1 part \\
\hline 4. & Amrita (Tinosporacordifolia) stem & Q. S. for Bhavana \\
\hline
\end{tabular}


Amalaki and Lauha Bhasma are the main ingredient of this yoga, hence it is named as Dhatri Lauha ${ }^{10}$. Yashtimadhu and Amrita are also active ingredients of Dhatri Lauha. The contents of Dhatri Lauha are Kashaya (astringent), Ruksha (dry), Sheeta (coolant) and Tridoshashamaka (pacifying vata-pitta-kapha). Amlaki is Rasayana (Rejuvenator), antioxidant, immuno-modulator and hepato-protective ${ }^{11}$. Yashtimadhu is again a rejuvenator and active bioavailability enhancer ${ }^{12}$. Amrita is rejuvenator and hepatoprotective. All these drugs collectively act on Rasavaha and Raktavaha Strotasa and facilitate replenishment of diminished Dhatus. Lauha bhasma has hematinic properties. Amlaki $^{13}$ and Amrita $^{14}$ are rich in Vitamin $\mathrm{C}$ there by enhance iron absorption also. Hence all these drugs collectively improve metabolism, iron absorption, blood formation and other objective parameters of Pandu Roga.

\section{CONCLUSION}

Overall comparison of the therapy showed that the results were found better with high percentage relief in the patients under Trial Group i.e. Dhatri Lauha in comparison to the Control Group. The study revealed that the selected management has better potential effects on Pandu Roga with the added advantage of being free from side effects. Dhatri Lauha has proved to be quite effective in the treatment of Pandu Roga. The drug effectively reduced the signs and symptoms of Pandu Roga as well as provided highly significant results in hematological parameters without involving undesirable side effects. However, this is a time bound small study on a very few numbers of patients of Pandu Roga and with limited resources. Therefore, it is proposed that the same project may be conducted on a longer series of patients with more scientific parameters to reach concrete conclusions.

\section{REFERENCES}

1. Geneva: world health organization; 2001.iron deficiency anemia assessment, prevention and control.

2. World health organiza xtion. nutritional anemia report of a WHO scientific group
3. Mohan Harsh, Textbook of Pathology, Jaypee Brothers Medical publishers (p) Ltd., New Delhi. Fifth Edition 2005.

4. Pandit Kashinath Shastri and Dr. Gorakhnath Chaturvedi, Charaka Samhita Vidyotani Tika, Sutra Sthana Chapter 19, verse no. 3 (4) Pg389, Edition 2009.

5. Pandit Kashinath Shastri and Dr. Gorakhnath Chaturvedi, Charaka Samhita Vidyotani Tika, ChikitsaSthana Chapter 16, Pg486, Edition 2009.

6. Pandit Kashinath Shastri and Dr. Gorakhnath Chaturvedi, Charaka Samhita Vidyotani Tika, ChikitsaSthana Chapter 16, verse no. 4-6, Pg487, Edition 2009.

7. Vaidya JadavajiTrikamji Acharya, Narayanram Acharya Kavyatirtha(editor). Commentary: Nibandhsangraha of Dalhanacharya on Sushrut Samhita of Sushruta, Uttar Tantra chapter 44, verse no. 3-5 Varanasi: Chowkhambha Surbharti Prakashan; Reprint 2003

8. Bhaishajya Ratnavali, Shula Rogadhikara, verse no. 142-147

9. Pandit Kashinath Shastri and Dr. Gorakhnath Chaturvedi, Charaka Samhita Vidyotani Tika, Chikitsa Sthana Chapter 16, verse no. 17,18; Pg489, Edition 2009.

10. Baishajya Ratnavali, Shula Rogadhikara, verse no. 142-147

11. Bhaskarmurthy D. H. et al. Hepatoprotective and antioxidant activity of standardized herbal extracts. Pharmacogn Mag. 2012; 8:116-23.

12. Drabu S. et al. Use of herbal bio enhancers to increase the bio availability of drugs. Res J Pharm Biol Chem Sci. 2011; 2:107-1.

13. Yadav V. et al. Amla (Emblica officinalis) - Medicinal food and pharmacological activity. Int J Pharm chem. Sci. 2014; 2:616-9.

14. Deshmukh A. et al. in vitro effect of Tinosporacordifolia on PMN function Update Ayurveda-94, Bombay, India; $24^{\text {th }}-26^{\text {th }}$ February. $1994: 63$

\section{Source of Support: Nil \\ Conflict of Interest: None Declared}

How to cite this URL: Roshi Mahajan \& Ankita: A Comparative Clinical Study of A Herbo-Mineral Compound Dhatri Lauha With A Control Known Drug In The Management Of Pandu Roga W.S.R. To Iron Deficiency Anemia. International Ayurvedic Medical Journal \{online\} 2021 \{cited April, 2021\} Available from: http://www.iamj.in/posts/images/upload/725 730.pdf 